\title{
APLIKASI SENSOR KELEMBABAN DAN FLEX SENSOR BERBASIS ARDUINO UNO UNTUK SISTEM PENDETEKSI LONGSOR
}

\author{
Rustan $^{1 *}$, Jesi Pebralia ${ }^{1}$, Tika Restianingsih ${ }^{1}$, Fratica Deswardani ${ }^{1}$, Mardian Peslinof ${ }^{1}$, \\ Nurhidayah ${ }^{1}$, Iful Amri ${ }^{2}$ \\ ${ }^{1}$ Program Studi Fisika, Fakultas Sains dan Teknologi, Universitas Jambi,36361, Indonesia \\ ${ }^{2}$ Program Studi Teknik Elektronika, Politeknik Jambi, 36361, Indonesia \\ *e-mail: rustan.rustan@unja.ac.id
}

\begin{abstract}
ABSTRAK
Deteksi dini tanah longsor sangat penting dilakukan untuk meminimalkan jumlah korban jiwa. Perkembangan teknologi memungkinkan manusia untuk memprediksi tanda-tanda longsor lebih akurat, cepat, dan ilmiah. Pada penelitian ini telah dilakukan pengujian sensor untuk mengukur parameter bencana longsor yaitu sensor kelembaban untuk mengukur kadar air tanah dan flex sensor untuk mengukur pergerakan tanah. Sensor tersebut dikendalikan menggunakan mikrokontroller Arduino Uno. Untuk melihat kemampuan sensor tersebut dilakukan uji fungsionalitas. Uji fungsionalitan dilakukan dengan menggunakan metode unit testing. Metode unit testing dilakukan dengan cara membandingkan hasil pengujian fungsional masing-masing sensor terhadap respon yang diharapkan. Uji fungsionalitas sensor kelembaban menunjukkan bahwa sensor mampu merespon perubahan kadar air dalam tanah dengan adanya perubahan tegangan. Persamaan linier yang dihasilkan dari kalibrasi sensor kelembaban yaitu $y=0,2179 x+3,2028$ dengan $R^{2}=0,99$ untuk kelembaban $<12,5 \%$ dan $y=-0,0265 x+0,7305$ dengan $R^{2}=0,98$ untuk kelembaban $>12,5 \%$. Uji fungsionalitas flex sensor menunjukkan bahwa sensor mampu mendeteksi pergerakan tanah dengan adanya perubahan tegangan. Persamaan linier yang dihasilkan dari kalibrasi flex sensor yaitu $y=-4,887 x+2517,2$ dengan $R^{2}=1$. Hal ini menunjukkan bahwa sensor kelembaban dan flex sensor cukup bagus untuk diimplementasikan dalam perancangan sistem pendeteksi longsor.
\end{abstract}

Kata Kunci: Sensor Kelembaban; Flex Sensor; Deteksi Longsor; Arduino Uno.

ABSTRACT

[Title: Application of Humidity Sensor and Flex Sensor based on Microcontroller Arduino Uno for LandslideDetection System] Early detection of landslides is very important to minimize the number of deaths. Technological developments allow humans to predict the signs of landslides more accurately, quickly, and scientifically. In this study, sensors were tested to measure landslide disaster parameters, namely humidity sensors to measure soil moisture and flex sensors to measure soil movement. The sensor is controlled using a microcontroller Arduino Uno. A functionality test was carried out to test the ability of the sensors. The functionality test was carried out using the unit testing method. The unit testing method is carried out by comparing the functional test results of each sensor to the expected response. The moisture sensor functionality test shows that the sensor is able to respond to changes in water content in the soil with changes in voltage. The linear equation resulting from the calibration of the humidity sensor is $y=0,2179 x$ $+3,2028$ with $R^{2}=0.99$ for humidity $>12,5 \%$ and $y=-0,0265 x+0,7305$ with $R^{2}=0,98$ for humidity $>12,5 \%$. The flex sensor functionality test shows that the sensor is able to detect soil movement in the presence of changes in voltage. The linear equation resulting from the flex sensor calibration is $y=-4,887 x+2517,2$ with $R^{2}=1$. This shows that the humidity sensor and flex sensor are good enough to be applied in the design of a landslide detection system.

Keywords: Humidity Sensor; Flex Sensor; Landslide Detection; Arduino Uno.

\section{PENDAHULUAN}

Indonesia memiliki wilayah yang sangat rawan bencana dan berada pada urutan kedua di dunia sebagai negara paling rawan bencana alam (Vos et al., 2010). Rata-rata setiap tahun terdapat 1000 kali kejadian bencana alam di Indonesia pada kurun waktu tahun 2008 sampai dengan 2017, yang didominasi oleh bencana hidrometereologi dan geofisika seperti banjir, tanah longsor, dan puting beliung (Amri et al., 2018). Berdasarkan data Badan Nasional Penanggulangan Bencana (BNPB) dalam 10 tahun terakhir yaitu dari tahun 2011 - 2020 telah terjadi sebanyak 7000 kejadian tanah longsor, terbanyak ketiga setelah banjir dan puting beliung.

Tanah longsor adalah perpindahan massa tanah, batuan, material rombakan, atau campuran material tersebut, bergerak menuruni lereng dengan kecepatan tertentu (Glade \& Crozier, 2005). Peristiwa tanah longsor dipengaruhi oleh beberapa faktor diantaranya curah hujan, kemiringan lereng, karakteristik tanah (Apriyono, 2009; Isnaini, 2019). 
Upaya untuk prediksi dan deteksi dini tanah longsor sangat penting dilakukan untuk menekan jumlah korban jiwa akibat bencana ini. Perkembangan teknologi memungkinkan manusia untuk memprediksi tanda-tanda longsor lebih akurat, cepat, dan ilmiah. Semakin banyak parameter tanda-tanda longsor yang diukur, maka semakin akurat prediksi potensi longsor di suatu tempat (Hidayat, 2017).

Penelitian tentang sistem deteksi dan peringatan dini tanah longsor telah dilakukan peneliti sebelumnya menggunakan teknologi penginderaan jauh (Ckhotimah et al., 2020; Somantri, 2008; Van Westen, 2013). Teknologi penginderaan jauh pada prinsipnya mengambil citra permukaan tanah dari udara menggunakan satelit maupun drone untuk memonitor pergeseran tanah dari waktu ke waktu. Metode ini memiliki kelebihan yaitu dapat memonitoring pergerakan tanah dalam skala besar di suatu daerah. Namun citra yang dihasilkan memiliki resolusi rendah karena hanya bisa mendeteksi pergerakan tanah dalam orde beberapa centimeter. Selain itu metode ini tidak cocok digunakan untuk mendeteksi tanah longsor lokal (Tofani et al., 2013)

Penelitian lain terkait sistem deteksi dini tanah longsor menggunakan teknologi sensor melalui pengukuran langsung pada permukaan tanah (Biansoongnern et al., 2016; Susanto et al., 2019; Utomo \& Irawan, 2017). Metode ini prinsipnya mengukur parameter tanda-tanda longsor seperti rekahan tanah, curah hujan, kemiringan lereng, getaran tanah, dan regangan tanah menggunakan sensor.Penelitian sistem deteksi dini tanah longsor dengan teknologi sensor umumnya belum mengaplikasikan sensor terpadu dan hanya fokus pada salah satu atau beberapa faktor pemicu pergerakan tanah. Priyanto et al. (2015) menggunakan sensor Linie Variable Differential Transformer (LVDT) dan 5 buah potensiometer yang terhubung secara paralel satu sama lain dengan menggunakan kawat sehingga ketika tanah bergeser maka tali akan menarik sensor LVDT dan Potensiometer. Perubahan nilai resistansi potensiometer dikonversi sebagai jarak pergeseran tanah. Metode ini rentan mengalami kesalahan data karena kawat penghubung bisa saja bergerak bukan karena gerakan tanah akan tetapi karena tertarik oleh hewan atau manusia yang melintas. Mardhatillah \& Wildian (2017) membuat sistem peringatan dini tanah longsor tanpa menggunakan tali yaitu menggunakan metode penginderaan berat. Sistem tersebut terdiri dari pegas yang dilengkapi dengan sensor Light Emitted Diode (LED) dan fotodioda pada masing-masing ujung pegas. Ketika terdapat pergeseran tanah, maka berat tanah akan menekan pegas sehingga membuat jarak antara LED dan fotodioda akan berubah dan akan mengaktifkan alarm peringatan dini. Namun metode ini hanya mengukur pergeseran tanah, padahal tanda-tanda tanah longsor tidak hanya dilihat dari pergeseran tanah melainkan banyak factor lain seperti curah hujan, kelembaban, dan kemiringan tanah.

Pada penelitian ini dilakukan pengujian sensor untuk mengukur parameter bencana longsor yaitu sensor kelembaban untuk mengukur kadar air tanah dan flex sensor untuk mengukur pergerakan tanah. Penelitian ini bertujuan untuk melihat kemampuan sensor kelembaban dan flex sensor sebelum diterapkan dalam perancangan sistem pendeteksi longsor.

\section{METODE}

Dalam penelitian ini sensor yang digunakan adalah sensor kelembaban tanah untuk mengukur kadar air dalam tanah dan flex sensor yang menunjukkan pergeseran tanah. Sensor tersebut dikontrol menggunakan Arduino Uno R3. Sensor kelembaban dan flex sensor dapat dilihat pada gambar 1 .

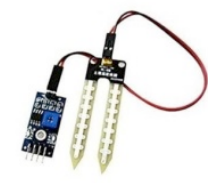

(a)

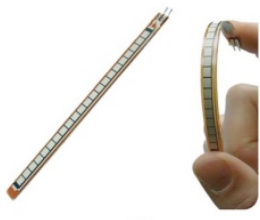

(b)
Gambar 1. (a) Sensor Kelembaban (b) Flex Sensor

Sensor kelembaban tanah mempunyai 2 Modul yaitu sensor untuk deteksi kelembaban dan module elektroniknya sebagai amplifier sinyal. Pada saat diberikan catudaya dan disensingkan pada tanah, maka nilai Output Analog akan berubah sesuai dengan kondisi kadar air dalam tanah. Tampilan modul eketronik sensor kelembaban dapat dilihat pada gambar 2 .

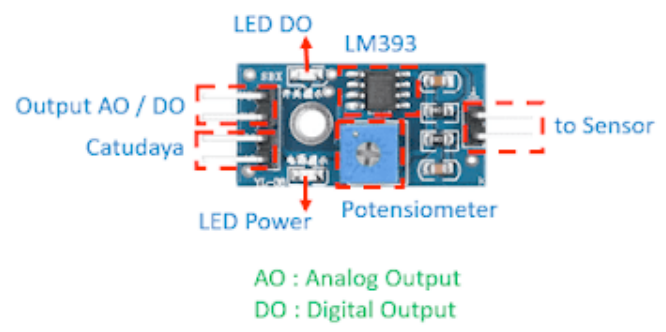

Gambar 2. Bagian modul elektronik

Sensor flex merupakan sensor yang mengukur besarnya defleksi atau tekukan sehingga terjadi perubahan resistansi elemen sensor (Saggio 
dan Orengo, 2018). Ketika sensor flex ditancapkan ke tanah, dan tanah tersebut mengalami pergerakan maka akan menekuk sensor sehingga sensor mengalami perubahan nilai dan dapat dikonversi menjadi jarak pergeseran tanah.

Arduino Uno merupakan mikrokontroller berbasis Atmega328. Arduino Uno terdiri dari 14 pin input/output dengan rincian 6 pin digunakan sebagai output PWM, 6 analog input, koneksi USB, power, dan tombolreset. Arduino Uno dapat dihubungkan dengan komputermenggunakankabel. Arduino Uno memiliki kelebihan karena bersifat open source. Tampilan Arduinu Uno dapat dilihat pada gambar 3.

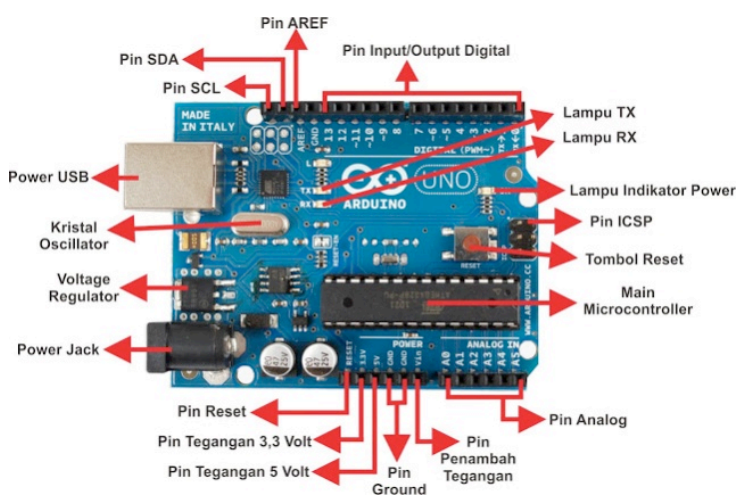

Gambar 3. Tampilan Arduino Uno

Perancangan perangkat lunak dilakukan dengan program arduino IDE. Program berisi algoritma dan perintah untuk pengambilan keputusan memberikan peringatan dini terhadap tanda-tanda longsor. Pengujian dilakukan terhadap sensor kelembaban terlebih dahulu.Uji fungsionalitas sensor kelembabandilakukan dengan menggunakan metode unit testing. Metode unit testing dilakukan dengan cara membandingkan hasil pengujian fungsional masing-masing komponen terhadap respon yang diharapkan. Jika respon menunjukkan kinerja yang baik dan stabil maka komponen siap untuk digunakan. Tampilan arduino IDE dapat dilihat pada gambar 4 .

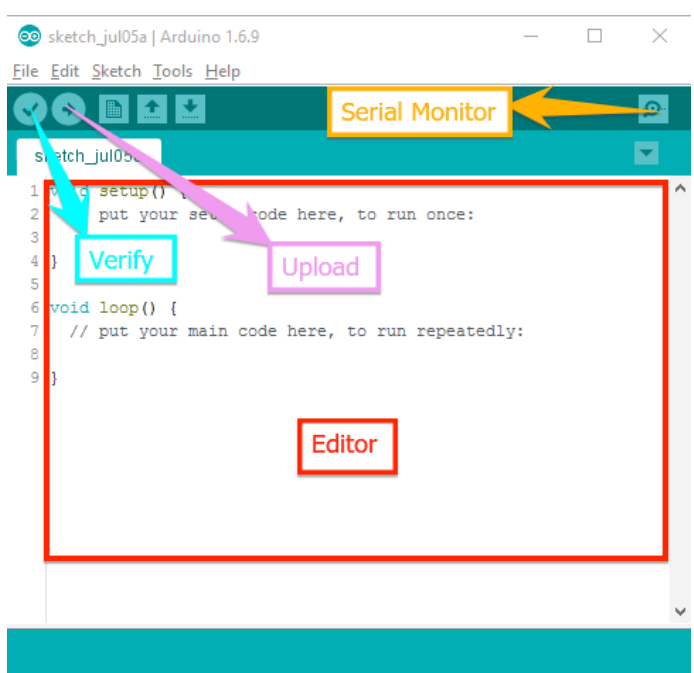

Gambar 4. Tampilan Arduino IDE

Analisis data menggunakan persamaan regresi linier di Microsoft Excel dengan menghubungkan antara besaran kadar air dengan tegangan sensor kelembaban dan besaran jarak dengan tegangan sensor flex.

\section{HASIL DAN PEMBAHASAN}

Alat deteksi longsor ini dirancang untuk dapat mendeteksi longsor secara dini. Untuk mengetahui kinerja dari sensor yang terdapat dalam sistem alat deteksi longsor, maka dilakukan pengujian komponen sensor. Pengujian fungsional sensor kelembaban dilakukan dengan menguji sensor terhadap tanah yang diberi air dengan kadar tertentu. Air akan menyebabkan terjadi perubahan kelembaban tanah.

Selanjutnya, untuk mengetahui respon sensor kelembaban tanah maka perlu dilakukan proses kalibrasi. Tahap pertama adalah menyiapkan tanah yang telah dikeringkan dan disaring sebagai objek dalam pengukuran, air yang digunakan untuk membasahi tanah, dan neraca untuk mengukur massa tanah dan massa air, sensor kelembaban sebagai untuk mengukur kadar air dalam tanah, dan mikrokontroller arduino uno yang digunakan untuk mengatur seluruh proses dalam pengukuran kelembaban.

Setelah semua alat dan bahan telah disiapaan maka proses kalibrasi dapat dilakukan. Proses kalibrasi dilakukan dengan dengan cara menetapkan massa tanah sebesar $200 \mathrm{~g}$ dan penambahan air setiap $2,5 \%$ dari massa tanah, yaitu 5 g. Gambar 5 menunjukkan hasil respon sensor kelembaban. 


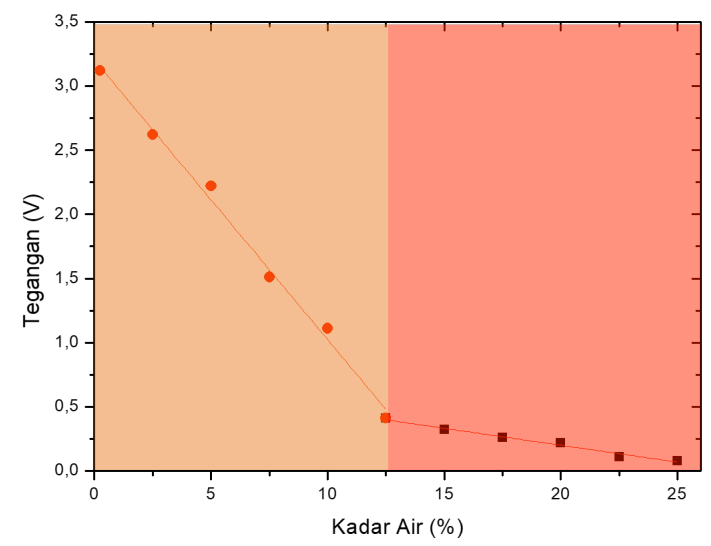

Gambar 5. Kurva tegangan terhadap kadar air dari pengujian sensor kelembaban

Gambar 5 menunjukkan semakin tinggi kadar air pada tanah, maka tegangan yang terukur semakin menurun. Hal ini menunjukkan adanya respon yang diberikan sensor berupa keluaran tegangan saat terjadi perubahan kadar air tanah. Semakin tinggi kadar air pada tanah tersebut, maka kelembaban tanah semakin tinggi. Berdasarkan Gambar 5, maka daerah pengukuran kadar air pada sensor kelembaban dapat dibagi menjadi dua daerah pengukuran, yaitu warna orange dan merah. Perbedaan daerah pengukuran ini dibatasi oleh kadar air sebesar 12,5\%.

Pada daerah pengukuran berwarna orange yaitu pengukuran dengan kadar air 12,5\%. Pada daerah ini diperoleh resposn sensor berupa linier dengan mengikuti persamaan 1 dengan nilai $\mathrm{R}^{2}=0,99$. Sedangkan pada daerah pengukuran berwarna merah yaitu pengukuran dengan kadar air $>12,5 \%$. Pada daerah ini diperoleh respon sensor berupa linier dengan mengikuti persamaan 2 dengan nilai $\mathrm{R}^{2}=0.98$.

$$
\begin{gathered}
y=0,2179 x+3,2028 \\
y=0,0265 x+0,7305
\end{gathered}
$$

Berdasarkan respon yang ditujukkan oleh sensor kelembaban terhadap kadar air dalam tanah, maka dapat dinyatakan bahwa sensor tersebut dapat diaplikasikan sistem pendeteksi longsor. Kadar air dalam tanah ini berhubungan lurus terhadap kelembaban tanah. Ketika kelembaban tanah semakin meningkat, maka potensi suatu dataran untuk longsor juga akan semakin tinggi.

Pengujian selanjutnya adalah untuk fungsionalitas flex sensor. Flex sensor merupakan sensor untuk mendeteksi adanya perubahan gerak berupa lengkungan. Saat tanah mengalami perubahan gerak saat akan terjadi longsor, maka akan ada perubahan lengkungan. Perubahan inilah yang dideteksi oleh flex sensor dalam sistem alat deteksi longsor.

Pengujian flex sensor dilakukan degan cara membandingkan keluaran tegangan dari flex sensor terhadap hasil pengukuran yang dibaca oleh digital caliper. Gambar 6 menunjukkan perubahan tegangan saat terhadap perubahan jarak yang dialami sensor.

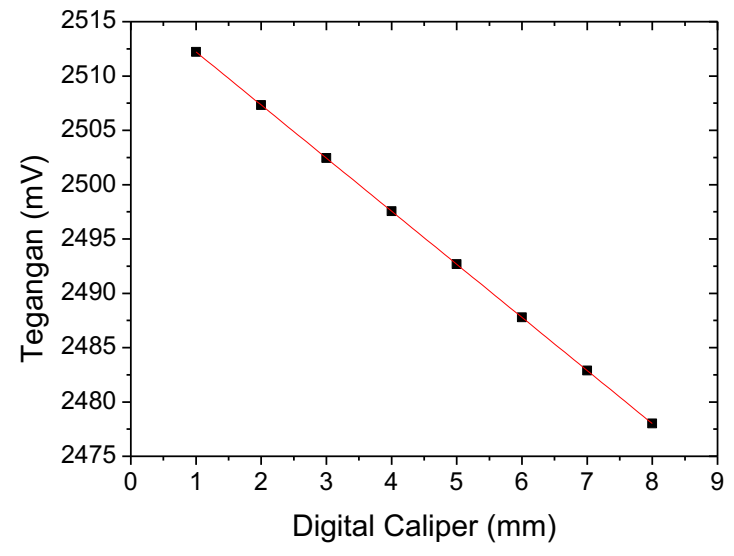

Gambar 6. Hasil uji fungsionalitas flex sensor

Berdasarkan Gambar 6, diperoleh hubungan linier dengan korelasi negatif antara tegangan dan jarak dengan mengikuti persamaan 3 dengan nilai $\mathrm{R}^{2}=1$.

$$
y=4,887 x+2517,2
$$

Semakin besar jarak yang dialami, menunjukkan bahwa tegangan yang terukur semakin kecil. Hal ini menunjukkan bahwa saat terjadi perubahan jarak terjadi respon berupa perubahan tegangan. Selain itu, resolusi terkecil yang dapat diukur adalah sebesar $1 \mathrm{~mm}$ dengan jarak maksimum yang dapat diukur yaitu $8 \mathrm{~mm}$. Hal ini menunjukkan bahwa flex sensor mampu mendeteksi perubahan jarak atau gerak dari tanah dan dapat diaplikasikan dalam mendeteksi pergeseran tanah dalam sistem pendeteksi tanah longsor.

\section{KESIMPULAN DAN SARAN}

Sensor kelembaban dan flex sensor dalam sistem alat deteksi longsor ini sudah memiliki kinerja yang baik dalam mendeteksi besaran yang dipantau. Hal ini menunjukkan bahwa sistem dapat terus dikembangkan agar mampu mendeteksi longsor secara cepat dan tepat.

\section{UCAPAN TERIMAKASIH}

Penelitian ini didanai oleh PNBP Fakultas Sains dan Teknologi (FST) Universitas Jambi tahun anggaran 2021. 


\section{DAFTAR PUSTAKA}

Amri, M. R., Yulianti, G., Yunus, R., Wiguna, S., W. Adi, A., Ichwana, A. N., \& Randongkir, Roling Evans Septian, R. T. (2018). RBI (Risiko Bencana Indonesia). Bnpb Direktorat Pengurangan Risiko Bencana, 9(3), 1-218.

Apriyono, A. (2009). Analisis penyebab tanah longsor di Kalitlaga Banjarnegara. Dinamika Rekayasa, 5(1), 14-18.

Biansoongnern, S., Plungkang, B., \& Susuk, S. (2016). Development of low cost vibration sensor network for early warning system of landslides. Energy Procedia, 89, 417-420.

Ckhotimah, H., Vonnisa, M., \& Budiman, A. (2020). Pemanfaatan data alos PALSAR untuk etimasi pergerakan tanah kota Padang upaya mitigasi bencana longsor. Jurnal Fisika Unand, 9(1), 93-99.

Glade, T., \& Crozier, M. J. (2005). The nature of landslide hazard impact. Landslide Hazard and Risk, 43-74.

Hidayat, T. (2017). Sistem Pendeteksi Dini Longsor Menggunakan Teknologi Wireless Sensor Network (WSN). Jurnal Teknik Elektro ITP, 6(1), 87-92.

Isnaini, R. (2019). Analisis Bencana Tanah Longsor di Wilayah Jawa Tengah. Islamic Management and Empowerment Journal, 1(2).

Mardhatillah, E., \& Wildian, W. (2017). Rancang Bangun Sistem Peringatan Dini Tanah Longsor Berbasis Mikrokontroler ATmega328 Menggunakan Metode Penginderaan Berat. Jurnal Fisika Unand, 6(2), 162-168.

Priyanto, J., Subagiyo, H., \& Madona, P. (2015). Rancang Bangun Peringatan Bahaya Longsor dan Monitoring Pergeseran Tanah Menggunakan Komunikasi Berbasis GSM.
Jurnal ELEMENTER. Vol, 1(2).

Saggio, G., \& Orengo, G. (2018). Flex sensor characterization against shape and curvature changes. Sensors and Actuators A: Physical, 273, 221-231.

Somantri, L. (2008). Kajian Mitigasi Bencana Longsor Lahan Dengan Menggunakan Teknologi Penginderaan Jauh. Semin. Ikat. Geogr. Indones, 1-10.

Susanto, E., Budiman, F., Mukhtar, D. P. H., \& Latief, M. H. (2019). Slope, humidity and vibration sensors performance for landslide monitoring system. 2019 IEEE Asia Pacific Conference on Wireless and Mobile (APWiMob), 139-142.

Tofani, V., Segoni, S., Agostini, A., Catani, F., \& Casagli, N. (2013). Use of remote sensing for landslide studies in Europe. Natural Hazards and Earth System Sciences, 13(2), 299-309.

Utomo, S. B., \& Irawan, J. F. (2017). A SensorBased of Detection Tools To Mitigate People Live in Areas Prone to Landslide. UNEJ EProceeding, 232-236.

Van Westen, C. J. (2013). Remote sensing and GIS for natural hazards assessment and disaster risk management. Treatise on Geomorphology, 3, 259-298.

Vos, F., Rodriguez, J., Below, R., \& Guha-Sapir, D. (2010). Annual disaster statistical review 2009: The numbers and trends. 